\title{
Split equality fixed point problem for quasi-pseudo-contractive mappings with applications
}

\author{
Shih-sen Chang ${ }^{1 *}$, Lin Wang ${ }^{2}$ and Li-Juan Qin³
}

${ }^{*}$ Correspondence:

changss2013@163.com

${ }^{1}$ Center for General Education,

China Medical University, Taichung,

40402, Taiwan

Full list of author information is

available at the end of the article

\begin{abstract}
In this paper, we consider a split equality fixed point problem for quasi-pseudo-contractive mappings which includes split feasibility problem, split equality problem, split fixed point problem etc., as special cases. A unified framework for the study of this kind of problems and operators is provided. The results presented in the paper extend and improve many recent results.
\end{abstract}

MSC: 49J40; 49J52; 47J20

Keywords: split equality fixed point problem; quasi-pseudo-contractive mapping; quasi-nonexpansive mapping; directed mapping; demicontractive mapping

\section{Introduction}

Let $C$ and $Q$ be nonempty closed and convex subsets of the real Hilbert spaces $H_{1}$ and $H_{2}$, respectively. The split feasibility problem $(S F P)$ is formulated as:

$$
\text { to find } x^{*} \in C \text { such that } A x^{*} \in Q \text {, }
$$

where $A: H_{1} \rightarrow H_{2}$ is a bounded linear operator. In 1994, Censor and Elfving [1] first introduced the SFP in finite-dimensional Hilbert spaces for modeling inverse problems which arise from phase retrievals and in medical image reconstruction [2]. It has been found that the SFP can also be used in various disciplines such as image restoration, computer tomography, and radiation therapy treatment planning [3-5]. The SFP in an infinite-dimensional real Hilbert space can be found in [2, 4, 6-10].

Recently, Moudafi [11-13] introduced the following split equality feasibility problem (SEFP):

$$
\text { to find } x \in C, y \in Q \text { such that } A x=B y \text {, }
$$

where $A: H_{1} \rightarrow H_{3}$ and $B: H_{2} \rightarrow H_{3}$ are two bounded linear operators. Obviously, if $B=I$ (identity mapping on $\mathrm{H}_{2}$ ) and $\mathrm{H}_{3}=H_{2}$, then (1.2) reduces to (1.1). The kind of split equality feasibility problems (1.2) allows asymmetric and partial relations between the variables $x$ and $y$. The interest is to cover many situations, such as decomposition methods for PDEs, applications in game theory and intensity-modulated radiation therapy.

(c) 2015 Chang et al. This article is distributed under the terms of the Creative Commons Attribution 4.0 International License (http://creativecommons.org/licenses/by/4.0/), which permits unrestricted use, distribution, and reproduction in any medium, provided you give appropriate credit to the original author(s) and the source, provide a link to the Creative Commons license, and indicate if changes were made. 
In order to solve split equality feasibility problem (1.2), Moudafi [11] introduced the following simultaneous iterative method:

$$
\left\{\begin{array}{l}
x_{k+1}=P_{C}\left(x_{k}-\gamma A^{*}\left(A x_{k}-B y_{k}\right)\right), \\
y_{k+1}=P_{Q}\left(y_{k}+\beta B^{*}\left(A x_{k+1}-B y_{k}\right)\right),
\end{array}\right.
$$

and under suitable conditions he proved the weak convergence of the sequence $\left\{\left(x_{n}, y_{n}\right)\right\}$ to a solution of (1.2) in Hilbert spaces.

In order to avoid using the projection, recently, Moudafi [13] introduced and studied the following problem: Let $T: H_{1} \rightarrow H_{1}$ and $S: H_{2} \rightarrow H_{2}$ be nonlinear operators such that $\operatorname{Fix}(T) \neq \emptyset$ and $\operatorname{Fix}(S) \neq \emptyset$, where $\operatorname{Fix}(T)$ and $\operatorname{Fix}(S)$ denote the sets of fixed points of $T$ and $S$, respectively. If $C=\operatorname{Fix}(T)$ and $Q=\operatorname{Fix}(S)$, then split equality problem (1.2) reduces to

$$
\text { find } x \in \operatorname{Fix}(T) \text { and } y \in \operatorname{Fix}(S) \text { such that } A x=B y \text {, }
$$

which is called a split equality fixed point problem (in short, SEFPP).

Denote by $\Gamma$ the solution set of split equality fixed point problem (1.4).

Recently Moudafi [13] proposed the following iterative algorithm for finding a solution of SEFPP (1.4):

$$
\left\{\begin{array}{l}
x_{n+1}=T\left(x_{n}-\gamma_{n} A^{*}\left(A x_{n}-B y_{n}\right)\right), \\
y_{n+1}=S\left(y_{n}+\beta_{n} B^{*}\left(A x_{n+1}-B y_{n}\right)\right) .
\end{array}\right.
$$

He also studied the weak convergence of the sequences generated by scheme (1.5) under the condition that $T$ and $S$ are firmly quasi-nonexpansive mappings. Very recently, Che and $\mathrm{Li}[14]$ proposed the following iterative algorithm for finding a solution of SEFPP (1.4):

$$
\left\{\begin{array}{l}
u_{n}=x_{n}-\gamma_{n} A^{*}\left(A x_{n}-B y_{n}\right) \\
x_{n+1}=\alpha_{n} x_{n}+\left(1-\alpha_{n}\right) T u_{n} \\
v_{n}=y_{n}+\gamma_{n} B^{*}\left(A x_{n}-B y_{n}\right) \\
y_{n+1}=\alpha_{n} y_{n}+\left(1-\alpha_{n}\right) S v_{n}
\end{array}\right.
$$

They also established the weak convergence of the scheme (1.6) under the condition that the operators $T$ and $S$ are quasi-nonexpansive mappings.

The purpose of this paper is two-fold. First, we will consider split equality fixed point problem (1.4) for the class of quasi-pseudo-contractive mappings which is more general than the classes of quasi-nonexpansive mappings, directed mappings, and demicontractive mappings. Second, we modify the iterative scheme (1.6) and propose the following iterative algorithms with weak convergence without using the projection:

$$
\left\{\begin{array}{l}
u_{n}=x_{n}-\gamma_{n} A^{*}\left(A x_{n}-B y_{n}\right) \\
x_{n+1}=\alpha_{n} x_{n}+\left(1-\alpha_{n}\right)((1-\xi) I+\xi T((1-\eta) I+\eta T)) u_{n} \\
v_{n}=y_{n}+\gamma_{n} B^{*}\left(A x_{n}-B y_{n}\right) \\
y_{n+1}=\alpha_{n} y_{n}+\left(1-\alpha_{n}\right)((1-\xi) I+\xi S((1-\eta) I+\eta S)) v_{n} .
\end{array}\right.
$$

Our results provide a unified framework for the study of this kind of problems and this class of operators. 


\section{Preliminaries}

In this section, we collect some definitions, notations, and conclusions, which will be needed in proving our main results.

Let $H$ be a real Hilbert space, $C$ be a nonempty closed convex subset of $H$, and $T: C \rightarrow C$ be a nonlinear mapping.

Definition 2.1 $T: C \rightarrow C$ is said to be:

(i) Nonexpansive if $\|T x-T y\| \leq\|x-y\| \forall x, y \in C$.

(ii) Quasi-nonexpansive if $\operatorname{Fix}(T) \neq \emptyset$ and

$$
\left\|T x-x^{*}\right\| \leq\left\|x-x^{*}\right\| \quad \forall x \in C \text { and } x^{*} \in \operatorname{Fix}(T) .
$$

(iii) Firmly nonexpansive if

$$
\|T x-T y\|^{2} \leq\|x-y\|^{2}-\|(I-T) x-(I-T) y\|^{2} \quad \forall x, y \in C .
$$

(iv) Firmly quasi-nonexpansive if $\operatorname{Fix}(T) \neq \emptyset$ and

$$
\left\|T x-x^{*}\right\|^{2} \leq\left\|x-x^{*}\right\|^{2}-\|(I-T) x\|^{2} \quad \forall x \in C \text { and } x^{*} \in \operatorname{Fix}(T) .
$$

(v) Strictly pseudo-contractive if there exists $k \in[0,1)$ such that

$$
\|T x-T y\|^{2} \leq\|x-y\|^{2}+k\|(I-T) x-(I-T) y\|^{2} \quad \forall x, y \in C .
$$

(vi) Directed if Fix $(T) \neq \emptyset$ and $\left\langle T x-x^{*}, T x-x\right\rangle \leq 0 \forall x \in C$ and $x^{*} \in \operatorname{Fix}(T)$.

(vii) Demicontractive if $\operatorname{Fix}(T) \neq \emptyset$ and there exists $k \in[0,1)$ such that

$$
\left\|T x-x^{*}\right\|^{2} \leq\left\|x-x^{*}\right\|^{2}+k\|T x-x\|^{2} \quad \forall x \in C \text { and } x^{*} \in \operatorname{Fix}(T) .
$$

Remark 2.2 As pointed out by Bauschke and Combettes [15], $T: C \rightarrow C$ is directed if and only if

$$
\left\|T x-x^{*}\right\|^{2} \leq\left\|x-x^{*}\right\|^{2}-\|T x-x\|^{2} \quad \forall x \in C \text { and } x^{*} \in F(T) .
$$

That is to say that the class of directed mappings coincides with that of firmly quasinonexpansive mappings.

Remark 2.3 From the above definitions, we note that the class of demicontractive mappings is fundamental; it includes many kinds of nonlinear mappings such as the directed mappings, the quasi-nonexpansive mappings, and the strictly pseudo-contractive mappings with fixed points as special cases.

Definition 2.4 An operator $T: C \rightarrow C$ is said to be pseudo-contractive if

$$
\langle T x-T y, x-y\rangle \leq\|x-y\|^{2} \quad \forall x, y \in C .
$$


The interest of pseudo-contractive operators lies in their connection with monotone mappings, namely, $T$ is a pseudo-contraction if and only if $I-T$ is a monotone mapping. It is well known that $T$ is pseudo-contractive if and only if

$$
\|T x-T y\|^{2} \leq\|x-y\|^{2}+\|(I-T) x-(I-T) y\|^{2} \quad \forall x, y \in C .
$$

Definition 2.5 An operator $T: C \rightarrow C$ is said to be quasi-pseudo-contractive if $\operatorname{Fix}(T) \neq \emptyset$ and

$$
\left\|T x-x^{*}\right\|^{2} \leq\left\|x-x^{*}\right\|^{2}+\|T x-x\|^{2} \quad \forall x \in C \text { and } x^{*} \in F(T) .
$$

It is obvious that the class of quasi-pseudo-contractive mappings includes the class of demicontractive mappings.

Definition 2.6 (1) A mapping $T: C \rightarrow C$ is said to be demiclosed at 0 if, for any sequence $\left\{x_{n}\right\} \subset C$ which converges weakly to $x$ and with $\left\|x_{n}-T\left(x_{n}\right)\right\| \rightarrow 0, T(x)=x$.

(2) A mapping $T: H \rightarrow H$ is said to be semi-compact if, for any bounded sequence $\left\{x_{n}\right\} \subset H$ with $\left\|x_{n}-T x_{n}\right\| \rightarrow 0$, there exists a subsequence $\left\{x_{n_{i}}\right\} \subset\left\{x_{n}\right\}$ such that $\left\{x_{n_{i}}\right\}$ converges strongly to some point $x \in H$.

Lemma 2.7 Let $H$ be a real Hilbert space. For any $x, y \in H$, the following conclusions hold:

$$
\begin{aligned}
& \|t x+(1-t) y\|^{2}=t\|x\|^{2}+(1-t)\|y\|^{2}-t(1-t)\|x-y\|^{2}, \quad t \in[0 ; 1] \\
& \|x+y\|^{2} \leq\|x\|^{2}+2\langle y, x+y\rangle .
\end{aligned}
$$

Recall that a Banach space $X$ is said to satisfy Opial's condition, if for any sequence $\left\{x_{n}\right\}$ in $X$ which converges weakly to $x^{*}$,

$$
\limsup _{n \rightarrow \infty}\left\|x_{n}-x^{*}\right\|<\limsup _{n \rightarrow \infty}\left\|x_{n}-y\right\| \quad \forall y \in X \text { with } y \neq x^{*} .
$$

It is well known that every Hilbert space satisfies the Opial condition.

Lemma 2.8 Let $\left\{a_{n}\right\}$ be a sequence of nonnegative real numbers such that

$$
a_{n+1} \leq\left(1-\gamma_{n}\right) a_{n}+\delta_{n} \quad \forall n \geq 1
$$

where $\left\{\gamma_{n}\right\}$ is a sequence in $(0,1)$ and $\left\{\delta_{n}\right\}$ is a sequence such that

(1) $\sum_{n=1}^{\infty} \gamma_{n}=\infty$;

(2) $\limsup \sup _{n \rightarrow \infty} \frac{\delta_{n}}{\gamma_{n}} \leq 0$ or $\sum_{n=1}^{\infty}\left|\delta_{n}\right|<\infty$.

Then $\lim _{n \rightarrow \infty} a_{n}=0$.

Lemma 2.9 Let $H$ be a real Hilbert space and $T: H \rightarrow H$ be a L-Lipschitzian mapping with $L \geq 1$. Denote

$$
K:=(1-\xi) I+\xi T((1-\eta) I+\eta T) .
$$

If $0<\xi<\eta<\frac{1}{1+\sqrt{1+L^{2}}}$, then the following conclusions hold: 
(1) $\operatorname{Fix}(T)=\operatorname{Fix}(T((1-\eta) I+\eta T))=\operatorname{Fix}(K)$.

(2) If $T$ is demiclosed at 0 , then $K$ is also demiclosed at 0.

(3) In addition, if $T: H \rightarrow H$ is quasi-pseudo-contractive, then the mapping $K$ is quasi-nonexpansive, that is,

$$
\left\|K x-u^{*}\right\| \leq\left\|x-u^{*}\right\| \quad \forall x \in H \text { and } u^{*} \in \operatorname{Fix}(T)=\operatorname{Fix}(K) .
$$

Proof (1) If $x^{*} \in \operatorname{Fix}(T)$, it is obvious that $x^{*} \in \operatorname{Fix}(T((1-\eta) I+\eta T))$.

Conversely, if $x^{*} \in \operatorname{Fix}(T((1-\eta) I+\eta T))$, i.e., $x^{*}=T\left((1-\eta) x^{*}+\eta T x^{*}\right)$, letting $U=(1-$ $\eta) I+\eta T$, then $T U x^{*}=x^{*}$. Put $U x^{*}=y^{*}$. Then $T y^{*}=x^{*}$. Now we prove that $x^{*}=y^{*}$. In fact, we have

$$
\begin{aligned}
\left\|x^{*}-y^{*}\right\| & =\left\|x^{*}-U x^{*}\right\|=\left\|x^{*}-((1-\eta) I+\eta T) x^{*}\right\| \\
& =\eta\left\|x^{*}-T x^{*}\right\|=\eta\left\|T y^{*}-T x^{*}\right\| \leq L \eta\left\|y^{*}-x^{*}\right\| .
\end{aligned}
$$

Since $0<L \eta<1$, we have $x^{*}=y^{*}$, i.e., $x^{*} \in \operatorname{Fix}(T)$. This shows that $\operatorname{Fix}(T)=\operatorname{Fix}(T((1-\eta) I+$ $\eta T)$ ).

It is obvious that $x \in \operatorname{Fix}(K)$ if and only if $x \in \operatorname{Fix}(T((1-\eta) I+\eta T))$.

The conclusion (1) is proved.

(2) For any sequence $\left\{x_{n}\right\} \subset H$ satisfying $x_{n} \rightarrow x^{*}$ and $\left\|x_{n}-K x_{n}\right\| \rightarrow 0$. Next we show that $x^{*} \in \operatorname{Fix}(K)$. From conclusion (1), we only need to prove that $x^{*} \in \operatorname{Fix}(T)$. In fact, since $T$ is $L$-Lipschizian, we have

$$
\begin{aligned}
\left\|x_{n}-T x_{n}\right\| & \leq\left\|x_{n}-T((1-\eta) I+\eta T) x_{n}\right\|+\left\|T((1-\eta) I+\eta T) x_{n}-T x_{n}\right\| \\
& \leq \frac{1}{\xi}\left\|x_{n}-(1-\xi) x_{n}-\xi T((1-\eta) I+\eta T) x_{n}\right\|+L \eta\left\|x_{n}-T x_{n}\right\| \\
& =\frac{1}{\xi}\left\|x_{n}-K x_{n}\right\|+L \eta\left\|x_{n}-T x_{n}\right\| .
\end{aligned}
$$

Simplifying it, we have

$$
\left\|x_{n}-T x_{n}\right\| \leq \frac{1}{\xi(1-L \eta)}\left\|x_{n}-K x_{n}\right\| \rightarrow 0
$$

Since $T$ is demiclosed at 0 , we have $x^{*} \in F(T)=F(K)$. The conclusion (2) is proved.

The conclusion (3) is obvious (see also [16]).

\section{Main results}

Throughout this section, we assume that:

(1) $H_{1}, H_{2}$, and $H_{3}$ are three real Hilbert spaces. $A: H_{1} \rightarrow H_{3}$ and $B: H_{2} \rightarrow H_{3}$ are two bounded linear operators with their adjoints $A^{*}$ and $B^{*}$, respectively;

(2) $T: H_{1} \rightarrow H_{1}$ and $S: H_{2} \rightarrow H_{2}$ are two $L$-Lipschitzian and quasi-pseudo-contractive mappings with $L \geq 1, \operatorname{Fix}(T) \neq \emptyset$, and $\operatorname{Fix}(S) \neq \emptyset$.

In the sequel, we denote the strong convergence and weak convergence of a sequence $\left\{x_{n}\right\}$ to a point $x \in H$ by $x_{n} \rightarrow x$ and $x_{n} \rightarrow x$, respectively. 
Our object is to solve the following split equality fixed point problem:

to find $x^{*} \in \operatorname{Fix}(T), y^{*} \in F(S)$ such that $A x^{*}=B y^{*}$.

In the sequel we use $\Gamma$ to denote the set of solutions of (3.1), that is,

$$
\Gamma=\left\{\left(x^{*}, y^{*}\right) \in \operatorname{Fix}(T) \times \operatorname{Fix}(S) \text { such that } A x^{*}=B y^{*}\right\},
$$

and we assume that $\Gamma \neq \emptyset$.

Now, we present our algorithm for finding $\left(x^{*}, y^{*}\right) \in \Gamma$.

Algorithm 3.1 Initialization: Choose $\left\{\alpha_{n}\right\} \subset(0,1)$. Take arbitrary $x_{0} \in H_{1}, y_{0} \in H_{2}$.

Iterative steps: For a given current $x_{n} \in H_{1}, y_{n} \in H_{2}$ compute

$$
\left\{\begin{array}{l}
\text { (a) } u_{n}=x_{n}-\gamma_{n} A^{*}\left(A x_{n}-B y_{n}\right), \\
\text { (b) } x_{n+1}=\alpha_{n} x_{n}+\left(1-\alpha_{n}\right)\left(\left(1-\xi_{n}\right) I+\xi_{n} T\left(\left(1-\eta_{n}\right) I+\eta_{n} T\right)\right) u_{n}, \\
\text { (c) } v_{n}=y_{n}+\gamma_{n} B^{*}\left(A x_{n}-B y_{n}\right) \\
\text { (d) } y_{n+1}=\alpha_{n} y_{n}+\left(1-\alpha_{n}\right)\left(\left(1-\xi_{n}\right) I+\xi_{n} S\left(\left(1-\eta_{n}\right) I+\eta_{n} S\right)\right) v_{n} .
\end{array}\right.
$$

Theorem 3.2 Let $H_{1}, H_{2}, H_{3}, A, B, S, T, \Gamma,\left\{x_{n}\right\}$ and $\left\{y_{n}\right\}$ be the same as above. If $T$ and $S$ are demiclosed at 0 and the following conditions are satisfied:

(i) $\gamma_{n} \in\left(0, \min \left(\frac{1}{\|A\|^{2}}, \frac{1}{\|B\|^{2}}\right)\right) \forall n \geq 1$;

(ii) $0<a<\xi_{n}<\eta_{n}<b<\frac{1}{1+\sqrt{1+L^{2}}} \forall n \geq 1$.

Then the following conclusions hold:

(I) the sequence $\left(\left\{x_{n}, y_{n}\right\}\right)$ generated by (3.3) converges weakly to a solution of problem (3.1);

(II) In addition, if $S, T$ are also semi-compact, then $\left(\left\{x_{n}, y_{n}\right\}\right)$ converges strongly to a solution of problem (3.1).

Proof First we prove the conclusion (I).

For any given $(p, q) \in \Gamma$, then $p \in \operatorname{Fix}(T), q \in \operatorname{Fix}(S)$ and $A p=B q$. From (3.3)(a), we have

$$
\begin{aligned}
\left\|u_{n}-p\right\|^{2} & =\left\|x_{n}-\gamma_{n} A^{*}\left(A x_{n}-B y_{n}\right)-p\right\|^{2} \\
& =\left\|x_{n}-p\right\|^{2}+\gamma_{n}^{2}\left\|A^{*}\left(A x_{n}-B y_{n}\right)\right\|^{2}-2 \gamma_{n}\left\langle x_{n}-p, A^{*}\left(A x_{n}-B y_{n}\right)\right\rangle \\
& \leq\left\|x_{n}-p\right\|^{2}+\gamma_{n}^{2}\|A\|^{2}\left\|A x_{n}-B y_{n}\right\|^{2}-2 \gamma_{n}\left\langle A x_{n}-A p, A x_{n}-B y_{n}\right\rangle .
\end{aligned}
$$

Similarly, from (3.3)(c), we have

$$
\left\|v_{n}-q\right\|^{2} \leq\left\|y_{n}-q\right\|^{2}+\gamma_{n}^{2}\|B\|^{2}\left\|A x_{n}-B y_{n}\right\|^{2}+2 \gamma_{n}\left\langle B y_{n}-B q, A x_{n}-B y_{n}\right\rangle .
$$

Put

$$
\begin{aligned}
& K:=\left(1-\xi_{n}\right) I+\xi_{n} T\left(\left(1-\eta_{n}\right) I+\eta_{n} T\right), \\
& G:=\left(1-\xi_{n}\right) I+\xi_{n} S\left(\left(1-\eta_{n}\right) I+\eta_{n} S\right) .
\end{aligned}
$$

By the assumptions of Theorem 3.2, condition (ii) and Lemma 2.9, we know that the mappings $K$ and $G$ have the following properties: 
(1) Both $K$ and $G$ are quasi-nonexpansive;

(2) $\operatorname{Fix}(K)=\operatorname{Fix}(T)$ and $\operatorname{Fix}(G)=\operatorname{Fix}(S)$;

(3) $K$ and $G$ demiclosed at 0.

Hence from (3.3)(b) and (2.1) we have

$$
\begin{aligned}
\left\|x_{n+1}-p\right\|^{2} & \left.=\| \alpha_{n} x_{n}+\left(1-\alpha_{n}\right)\left(\left(1-\xi_{n}\right) I+\xi_{n} T\left(\left(1-\eta_{n}\right) I+\eta_{n} T\right)\right) u_{n}-p\right) \|^{2} \\
& =\left\|\alpha_{n}\left(x_{n}-p\right)+\left(1-\alpha_{n}\right)\left(K u_{n}-p\right)\right\|^{2} \\
& =\alpha_{n}\left\|x_{n}-p\right\|^{2}+\left(1-\alpha_{n}\right)\left\|K u_{n}-p\right\|^{2}-\alpha_{n}\left(1-\alpha_{n}\right)\left\|K u_{n}-x_{n}\right\|^{2} \\
& \leq \alpha_{n}\left\|x_{n}-p\right\|^{2}+\left(1-\alpha_{n}\right)\left\|u_{n}-p\right\|^{2}-\alpha_{n}\left(1-\alpha_{n}\right)\left\|K u_{n}-x_{n}\right\|^{2}
\end{aligned}
$$

Similarly from (3.3)(c) and (2.1) we have

$$
\left\|y_{n+1}-q\right\|^{2} \leq \alpha_{n}\left\|y_{n}-q\right\|^{2}+\left(1-\alpha_{n}\right)\left\|v_{n}-q\right\|^{2}-\alpha_{n}\left(1-\alpha_{n}\right)\left\|G v_{n}-y_{n}\right\|^{2} .
$$

Adding (3.6) and (3.7) and by virtue of (3.4) and (3.5), we have

$$
\begin{aligned}
\| x_{n+1} & -p\left\|^{2}+\right\| y_{n+1}-q \|^{2} \\
\leq & \alpha_{n}\left\|x_{n}-p\right\|^{2}+\alpha_{n}\left\|y_{n}-q\right\|^{2}+\left(1-\alpha_{n}\right)\left\|u_{n}-p\right\|^{2}+\left(1-\alpha_{n}\right)\left\|v_{n}-q\right\|^{2} \\
& -\alpha_{n}\left(1-\alpha_{n}\right)\left\|K u_{n}-x_{n}\right\|^{2}-\alpha_{n}\left(1-\alpha_{n}\right)\left\|G v_{n}-y_{n}\right\|^{2} \\
\leq & \alpha_{n}\left\|x_{n}-p\right\|^{2}+\left(1-\alpha_{n}\right)\left\{\left\|x_{n}-p\right\|^{2}+\gamma_{n}^{2}\|A\|^{2}\left\|A x_{n}-B y_{n}\right\|^{2}\right. \\
& \left.-2 \gamma_{n}\left\langle A x_{n}-A p, A x_{n}-B y_{n}\right\rangle\right\} \\
& +\alpha_{n}\left\|y_{n}-q\right\|^{2}+\left(1-\alpha_{n}\right)\left\{\left\|y_{n}-p\right\|^{2}+\gamma_{n}^{2}\|B\|^{2}\left\|A x_{n}-B y_{n}\right\|^{2}\right. \\
& \left.+2 \gamma_{n}\left\langle B y_{n}-B q, A x_{n}-B y_{n}\right\rangle\right\} \\
& -\alpha_{n}\left(1-\alpha_{n}\right)\left\|K u_{n}-x_{n}\right\|^{2}-\alpha_{n}\left(1-\alpha_{n}\right)\left\|G v_{n}-y_{n}\right\|^{2} \\
= & \left\|x_{n}-p\right\|^{2}+\left\|y_{n}-q\right\|^{2}+\gamma_{n}^{2}\left(1-\alpha_{n}\right)\left\{\|A\|^{2}+\|B\|^{2}\right\}\left\|A x_{n}-B y_{n}\right\|^{2} \\
& -\left(1-\alpha_{n}\right) 2 \gamma_{n}\left\{\left\langle A x_{n}-A p, A x_{n}-B y_{n}\right\rangle-\left\langle B y_{n}-B q, A x_{n}-B y_{n}\right\rangle\right\} \\
& -\alpha_{n}\left(1-\alpha_{n}\right)\left\{\left\|K u_{n}-x_{n}\right\|^{2}+\left\|G v_{n}-y_{n}\right\|^{2}\right\} \\
= & \left\|x_{n}-p\right\|^{2}+\left\|y_{n}-q\right\|^{2}+\gamma_{n}^{2}\left(1-\alpha_{n}\right)\left\{\|A\|^{2}+\|B\|^{2}\right\}\left\|A x_{n}-B y_{n}\right\|^{2} \\
& -\left(1-\alpha_{n}\right) 2 \gamma_{n}\left\|A x_{n}-B y_{n}\right\|^{2}-\alpha_{n}\left(1-\alpha_{n}\right)\left\{\left\|K u_{n}-x_{n}\right\|^{2}+\left\|G v_{n}-y_{n}\right\|^{2}\right\}
\end{aligned}
$$

(since $A p=B q$ )

$$
\begin{aligned}
= & \left\|x_{n}-p\right\|^{2}+\left\|y_{n}-q\right\|^{2}-\left(1-\alpha_{n}\right) \gamma_{n}\left(2-\gamma_{n}\left(\|A\|^{2}+\|B\|^{2}\right)\right)\left\|A x_{n}-B y_{n}\right\|^{2} \\
& -\alpha_{n}\left(1-\alpha_{n}\right)\left\{\left\|K u_{n}-x_{n}\right\|^{2}+\left\|G v_{n}-y_{n}\right\|^{2}\right\} .
\end{aligned}
$$

Since $\gamma_{n} \in\left(0, \min \left\{\frac{1}{\|A\|^{2}}, \frac{1}{\|A\|^{2}}\right\}\right), \gamma_{n}\|A\|^{2}<1$ and $\gamma_{n}\|B\|^{2}<1$. So $0<\gamma_{n}\left(\|A\|^{2}+\|B\|^{2}\right)<2$. This implies that $\gamma_{n}\left(2-\gamma_{n}\left(\|A\|^{2}+\|B\|^{2}\right)\right)>0$.

Putting

$$
X_{n}(p, q)=\left\|x_{n}-p\right\|^{2}+\left\|y_{n}-q\right\|^{2}
$$


hence (3.8) can be written as

$$
\begin{aligned}
X_{n+1}(p, q) \leq & X_{n}(p, q)-\left(1-\alpha_{n}\right) \gamma_{n}\left(2-\gamma_{n}\left(\|A\|^{2}+\|B\|^{2}\right)\right)\left\|A x_{n}-B y_{n}\right\|^{2} \\
& -\alpha_{n}\left(1-\alpha_{n}\right)\left\{\left\|K u_{n}-x_{n}\right\|^{2}+\left\|G v_{n}-y_{n}\right\|^{2}\right\} \\
\leq & X_{n}(p, q) .
\end{aligned}
$$

This implies that $\left\{X_{n}(p, q)\right\}$ is a non-increasing sequence, hence the $\operatorname{limit}_{n \rightarrow \infty} X_{n}(p, q)$ exists. Therefore the following limits exist:

$$
\lim _{n \rightarrow \infty}\left\|x_{n}-p\right\| \quad \text { and } \quad \lim _{n \rightarrow \infty}\left\|y_{n}-q\right\| \quad \forall(p, q) \in \Gamma .
$$

Rewritten (3.10) as

$$
\begin{aligned}
& \left(1-\alpha_{n}\right) \gamma_{n}\left(2-\gamma_{n}\left(\|A\|^{2}+\|B\|^{2}\right)\right)\left\|A x_{n}-B y_{n}\right\|^{2} \\
& \quad+\alpha_{n}\left(1-\alpha_{n}\right)\left\{\left\|K u_{n}-x_{n}\right\|^{2}+\left\|G v_{n}-y_{n}\right\|^{2}\right\} \leq X_{n}(p, q)-X_{n+1}(p, q) .
\end{aligned}
$$

Letting $n \rightarrow \infty$ and taking the limit in (3.12), we have

$$
\left\|A x_{n}-B y_{n}\right\| \rightarrow 0 ; \quad\left\|K u_{n}-x_{n}\right\| \rightarrow 0 ; \quad\left\|G v_{n}-y_{n}\right\| \rightarrow 0 .
$$

From (3.13) and (3.3) we have

$$
\left\{\begin{array}{l}
\lim _{n \rightarrow \infty}\left\|u_{n}-x_{n}\right\| \rightarrow 0 \text { and } \lim _{n \rightarrow \infty}\left\|v_{n}-y_{n}\right\| \rightarrow 0 \\
\quad \lim _{n \rightarrow \infty}\left\|x_{n+1}-x_{n}\right\| \\
\quad=\lim _{n \rightarrow \infty}\left(1-\alpha_{n}\right)\left\|\left(\left(1-\xi_{n}\right) I+\xi_{n} T\left(\left(1-\eta_{n}\right) I+\eta_{n} T\right)\right) u_{n}-x_{n}\right\| \\
\quad=\lim _{n \rightarrow \infty}\left(1-\alpha_{n}\right)\left\|K u_{n}-x_{n}\right\|=0 \\
\quad \lim _{n \rightarrow \infty}\left\|y_{n+1}-y_{n}\right\| \\
\quad=\lim _{n \rightarrow \infty}\left(1-\beta_{n}\right)\left\|\left(\left(1-\xi_{n}\right) S+\xi_{n} S\left(\left(1-\eta_{n}\right) I+\eta_{n} S\right)\right) y_{n}-y_{n}\right\| \\
\quad=\lim _{n \rightarrow \infty}\left(1-\alpha_{n}\right)\left\|G v_{n}-y_{n}\right\|=0
\end{array}\right.
$$

This together with (3.13) shows that

$$
\left\{\begin{array}{l}
\left\|K u_{n}-u_{n}\right\| \leq\left\|K u_{n}-x_{n}\right\|+\left\|x_{n}-u_{n}\right\| \rightarrow 0 ; \\
\left\|G v_{n}-v_{n}\right\| \leq\left\|G v_{n}-y_{n}\right\|+\left\|y_{n}-v_{n}\right\| \rightarrow 0 .
\end{array}\right.
$$

Since $\left\{x_{n}\right\}$ and $\left\{y_{n}\right\}$ are bounded sequences, there exist some weakly convergent subsequences, say $\left\{x_{n_{i}}\right\} \subset\left\{x_{n}\right\}$ and $\left\{y_{n_{i}}\right\} \subset\left\{y_{n}\right\}$ such that $x_{n_{i}} \rightarrow x^{*}$ and $y_{n_{i}} \rightarrow y^{*}$. Since every Hilbert space has the Opial property. The Opial property guarantees that the weakly subsequential limit of $\left\{\left(x_{n}, y_{n}\right)\right\}$ is unique. Therefore we have $x_{n} \rightarrow x^{*}$ and $y_{n} \rightarrow y^{*}$.

On the other hand, from (3.14), one gets $u_{n} \rightarrow x^{*}$ and $v_{n} \rightarrow y^{*}$. By (3.15) and the demiclosed property of $K$ and $G$, we have $K x^{*}=x^{*}$ and $G y^{*}=y^{*}$. This implies that $x^{*} \in \operatorname{Fix}(T)$ and $y^{*} \in \operatorname{Fix}(S)$.

Now we are left to show that $A x^{*}=B y^{*}$. In fact, since $A x_{n}-B y_{n} \rightarrow A x^{*}-B y^{*}$, by using the weakly lower semi-continuity of squared norm, we have

$$
\left\|A x^{*}-B y^{*}\right\|^{2}=\liminf _{n \rightarrow \infty}\left\|A x_{n}-B y_{n}\right\|^{2}=\lim _{n \rightarrow \infty}\left\|A x_{n}-B y_{n}\right\|^{2}=0 .
$$

Thus $A x^{*}=B y^{*}$. This completes the proof of the conclusion (I). 
Now we prove the conclusion (II). In fact, by virtue of (2.4), (3.13), and (3.14), we have

$$
\left\{\begin{array}{l}
\left\|x_{n}-T x_{n}\right\| \leq \frac{1}{\xi_{n}\left(1-L \eta_{n}\right)}\left\|x_{n}-K x_{n}\right\| \rightarrow 0 \\
\left\|y_{n}-S y_{n}\right\| \leq \frac{1}{\xi_{n}\left(1-L \eta_{n}\right)}\left\|y_{n}-G y_{n}\right\| \rightarrow 0 .
\end{array}\right.
$$

Since $S, T$ are semi-compact, it follows from (3.16) that there exist subsequences $\left\{x_{n_{i}}\right\} \subset$ $\left\{x_{n}\right\}$ and $\left\{y_{n_{j}}\right\} \subset\left\{y_{n}\right\}$ such that $x_{n_{i}} \rightarrow x$ (some point in $F(T)$ ) and $y_{n_{j}} \rightarrow y$ (some point in $F(S))$. It follows from (3.11), $x_{n} \rightarrow x^{*}$, and $y_{n} \rightarrow y^{*}$ that $x_{n} \rightarrow x^{*}$ and $y_{n} \rightarrow y^{*}$ and $A x^{*}=$ $B y^{*}$.

\section{Applications}

\subsection{Application to the split equality variational inequality problem}

Throughout this section, we assume that $H_{1}, H_{2}$, and $H_{3}$ are three real Hilbert spaces. $C$ and $Q$ both are nonempty and closed convex subsets of $H_{1}$ and $H_{2}$, respectively and assume that $A: H_{1} \rightarrow H_{3}$ and $B: H_{2} \rightarrow H_{3}$ are two bounded linear operator with its adjoint $A^{*}$ and $B^{*}$, respectively.

Let $M: C \rightarrow H_{1}$ be a mapping. The variational inequality problem for mapping $M$ is to find a point $x^{*} \in C$ such that

$$
\left\langle M x^{*}, z-x^{*}\right\rangle \geq 0 \quad \forall z \in C
$$

We will denote the solution set of (4.1) by $V I(M, C)$.

A mapping $M: C \rightarrow H_{1}$ is said to be $\alpha$-inverse-strongly monotone if there exists a constant $\alpha>0$ such that

$$
\langle M x-M y, x-y\rangle \geq \alpha\|M x-M y\|^{2} \quad \forall x, y \in C .
$$

It is easy to see that if $M$ is $\alpha$-inverse-strongly monotone, then $M$ is $\frac{1}{\alpha}$-Lipschitzian.

Setting $h(x, y)=\langle M x, y-x\rangle: C \times C \rightarrow \mathbb{R}$, it is easy to show that $h$ is an equilibrium function, i.e., it satisfies the following conditions, (A1)-(A4):

(A1) $h(x, x)=0$, for all $x \in C$;

(A2) $h$ is monotone, i.e., $h(x, y)+h(y, x) \leq 0$ for all $x, y \in C$;

(A3) $\lim \sup _{t \downarrow 0} h(t z+(1-t) x, y) \leq h(x, y)$ for all $x, y, z \in C$;

(A4) for each $x \in C, y \mapsto h(x, y)$ is convex and lower semi-continuous.

For given $\lambda>0$ and $x \in H$, the resolvent of the equilibrium function $h$ is the operator $R_{\lambda, h}: H \rightarrow C$ defined by

$$
R_{\lambda, h}(x):=\left\{z \in C: h(z, y)+\frac{1}{\lambda}\langle y-z, z-x\rangle \geq 0, \forall y \in C\right\} .
$$

Proposition 4.1 [17] The resolvent operator $R_{\lambda, h}$ of the equilibrium function $h$ has the following properties :

(1) $R_{\lambda, h}$ is single-valued;

(2) $\operatorname{Fix}\left(R_{\lambda, h}\right)=\operatorname{VI}(M, C)$, where $\operatorname{VI}(M, C)$ is the solution set of variational inequality

(4.1) which is a nonempty closed and convex subset of $C$;

(3) $R_{\lambda, h}$ is a firmly nonexpansive mapping. Therefore $R_{\lambda, h}$ is demiclosed at 0 . 
Let $T: C \rightarrow H_{1}$ and $S: Q \rightarrow H_{2}$ be two $\alpha$-inverse-strongly monotone mappings. The so-called split equality variational inequality problem with respect to $T$ and $S$ is to find $x^{*} \in C$ and $y^{*} \in Q$ such that

$$
\left\{\begin{array}{l}
\text { (a) }\left\langle T x^{*}, u-x^{*}\right\rangle \geq 0 \quad \forall u \in C, \\
\text { (b) }\left\langle S y^{*}, v-y^{*}\right\rangle \geq 0 \quad \forall v \in Q, \\
\text { (c) } A x^{*}=B y^{*} .
\end{array}\right.
$$

In the sequel we use $\Omega$ to denote the solution set of split equality variational inequality problem (4.4), i.e.,

$$
\Theta=\left\{\left(x^{*}, y^{*}\right) \in V I(T, C) \times V I(S, Q): A x^{*}=B y^{*}\right\},
$$

where $V I(T, C)$ (resp. $V I(S, Q))$ is the solution set of variational inequality (4.4)(a) (resp. $(4.4)(\mathrm{b}))$.

Denote by $f(x, y)=\langle T x, y-x\rangle: C \times C \rightarrow \mathbb{R}$ and $g(u, v)=\langle S u, v-u\rangle: Q \times Q \rightarrow \mathbb{R}$. For given $\lambda>0, x \in H_{1}$, and $u \in H_{2}$, let $R_{\lambda, f}(x)$ and $R_{\lambda, g}(u)$ be the resolvent operator of the equilibrium function $f$ and $g$, respectively, which are defined by

$$
R_{\lambda, f}(x):=\left\{z \in C: f(z, y)+\frac{1}{\lambda}\langle y-z, z-x\rangle \geq 0, \forall y \in C\right\}
$$

and

$$
R_{\lambda, g}(u):=\left\{z \in Q: g(z, v)+\frac{1}{\lambda}\langle v-z, z-u\rangle \geq 0, \forall v \in Q\right\} .
$$

It follows from Proposition 4.1 that

$$
\operatorname{Fix}\left(R_{\lambda, f}\right)=V I(T, C) \neq \emptyset ; \quad \operatorname{Fix}\left(R_{\lambda, g}\right)=V I(S, Q) \neq \emptyset,
$$

and so $R_{\lambda, f}$ and $R_{\lambda, g}$ both are quasi-pseudo-contractive and 1-Lipschitzian. Therefore the split equality variational inequality problem with respect to $T$ and $S(4.4)$ is equivalent to the following split equality fixed point problem:

$$
\text { to find } x^{*} \in \operatorname{Fix}\left(R_{\lambda, f}\right), y^{*} \in \operatorname{Fix}\left(R_{\lambda, g}\right) \text { such that } A x^{*}=B y^{*} \text {. }
$$

Since $R_{\lambda, f}$ and $R_{\lambda, g}$ are firmly nonexpansive with $\operatorname{Fix}\left(R_{\lambda, f}\right) \neq \emptyset$ and $\operatorname{Fix}\left(R_{\lambda, g}\right) \neq \emptyset$, the following theorem can be obtained from Theorem 3.2 immediately.

Theorem 4.2 Let $H_{1}, H_{2}, H_{3}, C, Q, A, B, T, S, R_{\lambda, f}, R_{\lambda, g}, \Theta$ be the same as above and assume that $\Theta \neq \emptyset$. For given $x_{0} \in C, y_{0} \in Q$, let $\left(\left\{x_{n}\right\},\left\{x_{n}\right\}\right)$ be the sequence generated by

$$
\left\{\begin{array}{l}
u_{n}=x_{n}-\gamma_{n} A^{*}\left(A x_{n}-B y_{n}\right) \\
x_{n+1}=R_{\lambda, f}\left(u_{n}\right) \\
v_{n}=y_{n}+\gamma_{n} B^{*}\left(A x_{n}-B y_{n}\right) \\
y_{n+1}=R_{\lambda, g}\left(v_{n}\right)
\end{array}\right.
$$

If $\gamma_{n} \in\left(0, \min \left(\frac{1}{\|A\|^{2}}, \frac{1}{\|B\|^{2}}\right)\right) \forall n \geq 1$, then the sequence $\left(\left\{x_{n}, y_{n}\right\}\right)$ generated by (4.8) converges weakly to a solution of split equality variational inequality problem (4.4). 


\subsection{Application to the split equality convex minimization problem}

Let $C$ be a nonempty closed convex subset of $H_{1}$ and $Q$ be a nonempty closed convex subset of $H_{2}$. Let $\phi: C \rightarrow \mathbb{R}$ and $\psi: Q \rightarrow \mathbb{R}$ be two proper and convex and lower semicontinuous functions and $A: H_{1} \rightarrow H_{3}$ and $B: H_{2} \rightarrow H_{3}$ be two bounded linear operator with its adjoint $A^{*}$ and $B^{*}$, respectively.

The so-called split equality convex minimization problem for $\phi$ and $\psi$ is to find $x^{*} \in C$, $y^{*} \in Q$ such that

$$
\phi\left(x^{*}\right)=\min _{x \in C} \phi(x), \quad \psi\left(y^{*}\right)=\min _{x \in Q} \psi(y), \quad \text { and } \quad A x^{*}=B y^{*} .
$$

In the sequel, we denote by $\Omega$ the solution set of split equality convex minimization problem (4.9), i.e.,

$$
\begin{gathered}
\Omega=\left\{(p, q) \in C \times Q \text { such that } \phi\left(x^{*}\right)=\min _{x \in C} \phi(x),\right. \\
\left.\psi\left(y^{*}\right)=\min _{x \in Q} \psi(y) \text { and } A x^{*}=B y^{*}\right\}
\end{gathered}
$$

Let $j(x, y):=\phi(y)-\psi(x): C \times C \rightarrow \mathbb{R}$ and $k(u, v):=\phi(v)-\psi(u): Q \times Q \rightarrow \mathbb{R}$. It is easy to see that $j$ and $k$ both are equilibrium functions satisfying the conditions (A1)-(A4).

For given $\lambda>0, x \in H_{1}$ and $u \in H_{2}$, we define the resolvent operators of $j$ and $k$ as follows:

$$
R_{\lambda, j}(x):=\left\{z \in C: j(z, y)+\frac{1}{\lambda}\langle y-z, z-x\rangle \geq 0, \forall y \in C\right\}
$$

and

$$
R_{\lambda, k}(u):=\left\{z \in Q: k(z, v)+\frac{1}{\lambda}\langle v-z, z-u\rangle \geq 0, \forall v \in Q\right\} .
$$

By the same argument as given in Section 4.1, we know that

$$
\operatorname{Fix}\left(R_{\lambda, j}\right)=\left\{x^{*} \in C: \phi\left(x^{*}\right)=\min _{x \in C} \phi(x)\right\}, \quad \operatorname{Fix}\left(R_{\lambda, k}\right)=\left\{y^{*} \in Q: \psi\left(y^{*}\right)=\min _{x \in Q} \psi(y)\right\} .
$$

Therefore the split equality convex minimization problem for $\phi$ and $\psi$ is equivalent to the following split equality fixed point problem:

$$
\text { to find } x^{*} \in \operatorname{Fix}\left(R_{\lambda, j}\right), y^{*} \in \operatorname{Fix}\left(R_{\lambda, k}\right) \text { such that } A x^{*}=B y^{*} \text {. }
$$

Since $R_{\lambda, j}$ and $R_{\lambda, k}$ both are firmly nonexpansive with $\operatorname{Fix}\left(R_{\lambda, f}\right) \neq \emptyset$ and $\operatorname{Fix}\left(R_{\lambda, g}\right) \neq \emptyset$, the following theorem can be obtained from Theorem 3.2 immediately.

Theorem 4.3 Let $H_{1}, H_{2}, H_{3}, C, Q, A, B, \phi, \psi, R_{\lambda, j}, R_{\lambda, k}, \Omega$ be the same as above and assume that $\Omega \neq \emptyset$. For given $x_{0} \in C, y_{0} \in Q$, let $\left(\left\{x_{n}\right\},\left\{x_{n}\right\}\right)$ be the sequence generated by

$$
\left\{\begin{array}{l}
u_{n}=x_{n}-\gamma_{n} A^{*}\left(A x_{n}-B y_{n}\right), \\
x_{n+1}=R_{\lambda, j}\left(u_{n}\right) \\
v_{n}=y_{n}+\gamma_{n} B^{*}\left(A x_{n}-B y_{n}\right), \\
y_{n+1}=R_{\lambda, k}\left(v_{n}\right) .
\end{array}\right.
$$




\title{
If $\gamma_{n} \in\left(0, \min \left(\frac{1}{\|A\|^{2}}, \frac{1}{\|B\|^{2}}\right)\right) \forall n \geq 1$, then the sequence $\left(\left\{x_{n}, y_{n}\right\}\right)$ generated by (4.12) converges weakly to a solution of split equality convex minimization problem (4.9).
}

\author{
Competing interests \\ The authors declare that they have no competing interests.
}

\section{Authors' contributions}

All authors read and approved the final manuscript.

\section{Author details}

${ }^{1}$ Center for General Education, China Medical University, Taichung, 40402, Taiwan. ${ }^{2}$ College of Statistics and Mathematics, Yunnan University of Finance and Economics, Kunming, Yunnan 650221, P.R. China. ${ }^{3}$ Department of Mathematics, Kunming University, Kunming, Yunnan 650214, China.

\section{Acknowledgements}

This work was supported by the National Natural Science Foundation of China (Grant No. 11361070).

Received: 1 September 2015 Accepted: 5 November 2015 Published online: 17 November 2015

\section{References}

1. Censor, Y, Elfving, T: A multiprojection algorithm using Bregman projections in a product space. Numer. Algorithms 8 , 221-239 (1994)

2. Byrne, C: Iterative oblique projection onto convex subsets and the split feasibility problem. Inverse Probl. 18, 441-453 (2002)

3. Censor, Y, Bortfeld, T, Martin, N, Trofimov, A: A unified approach for inversion problem in intensity-modulated radiation therapy. Phys. Med. Biol. 51, 2353-2365 (2006)

4. Censor, Y, Elfving, T, Kopf, N, Bortfeld, T: The multiple-sets split feasibility problem and its applications. Inverse Probl. 21, 2071-2084 (2005)

5. Censor, Y, Motova, A, Segal, A: Perturbed projections and subgradient projections for the multiple-sets split feasibility problem. J. Math. Anal. Appl. 327, 1244-1256 (2007)

6. Xu, HK: A variable Krasnosel'skii-Mann algorithm and the multiple-sets split feasibility problem. Inverse Probl. 22, 2021-2034 (2006)

7. Yang, Q: The relaxed CQ algorithm for solving the split feasibility problem. Inverse Probl. 20, 1261-1266 (2004)

8. Zhao, J, Yang, Q: Several solution methods for the split feasibility problem. Inverse Probl. 21, 1791-1799 (2005)

9. Chang, S-s, Agarwal, RP: Strong convergence theorems of general split equality problems for quasi-nonexpansive mappings. J. Inequal. Appl. 2014, Article ID 367 (2014)

10. Chang, S-S, Wang, L, Tang, YK, Wang, G: Moudafi's open question and simultaneous iterative algorithm for general split equality variational inclusion problems and general split equality optimization problems. Fixed Point Theory Appl. 2014, Article ID 215 (2014)

11. Moudafi, A: A relaxed alternating CQ algorithm for convex feasibility problems. Nonlinear Anal. 79, 117-121 (2013)

12. Moudafi, A, Al-Shemas, E: Simultaneous iterative methods forsplit equality problem. Trans. Math. Program. Appl. 1, 1-11 (2013)

13. Moudafi, A: Split monotone variational inclusions. J. Optim. Theory Appl. 150, 275-283 (2011)

14. Che, H, Li, M: A simultaneous iterative method for split equality problems of two finite families of strictly pseudononspreading mappings without prior knowledge of operator norms. Fixed Point Theory Appl. 2015, Article ID 1 (2015)

15. Bauschke, HH, Combettes, PL: A weak-to-strong convergence principle for Fejer-monotone methods in Hilbert spaces. Math. Oper. Res. 26, 248-264 (2001)

16. Yao, Y, Liou, Y-C, Yao, J-C: Split common fixed point problem for two quasi-pseudo-contractive operators and its algorithm construction. Fixed Point Theory Appl. 2015, Article ID 127 (2015)

17. Blum, E, Oettli, W: From optimization and variational inequalities to equilibrium problems. Math. Stud. 63(1-4), 123-145 (1994) 